\title{
Satisfaction and intention to return for donation among non-remunerated blood donors in a tertiary hospital in Malaysia
}

Pei Pei Tan

hospital raja permaisuri bainun

Chee Tao Chang ( $\nabla$ davidcct.crc@gmail.com )

hospital raja permaisuri bainun

Jernih Abdul Rahman

hospital raja permaisuri bainun

Sabariah Mohd Noor

hospital raja permaisuri bainun

Research Article

Keywords: blood donor, satisfaction, experience, intention to donate, Malaysia

Posted Date: April 7th, 2021

DOI: https://doi.org/10.21203/rs.3.rs-353981/v1

License: (1) This work is licensed under a Creative Commons Attribution 4.0 International License.

Read Full License 


\section{Abstract}

\section{Background}

In Malaysia, blood supply relies mainly on non-remunerated blood donors. This study aimed to assess the satisfaction and experience of blood donors during the blood donation process and their intention to return for donation in future.

\section{Materials and Methods}

This was a cross-sectional study conducting using a self-administered questionnaire among blood donors. Study was conducted in a tertiary referral hospital and two mobile sites in the Perak state of Malaysia. The questionnaire was initially developed in the Malay language with 5-point Likert scale. The questionnaire comprised of three domains: i) sociodemographic characteristics ii) donor's satisfaction towards staff iii) donors' experience and satisfaction towards the donation process.

\section{Result}

Of the 400 questionnaires distributed, 369 (92.3\%) were analysed. The mean age of the donors was $35.98 \pm 10.67$ years. Most of the donors were male (75.1\%), of Malay ethnicity $(60.2 \%)$ and regular donors (65.6\%). Majority of the blood donors reported high satisfaction towards the interviewer (99.0\%), blood taking skill of the staff (97.5\%), politeness and friendliness of the staff $(99.5 \%)$ and communication with the staff (98.9\%). Minority of the blood donors expressed dissatisfaction towards the parking spaces $(13.4 \%)$, refreshment $(0.8 \%)$, and the blood donation operation hours $(0.8 \%)$. Generally, the respondents had high overall satisfaction level (99.2\%) and high intention to donate blood again in the future (98.9\%).

\section{Conclusion}

Blood donors in the current study were highly satisfied towards the staff and blood donation process. Translation of high intention to return for donation to actual donation behaviour require further exploration in future studies.

\section{Introduction}

Maintaining a balanced blood supply and demand is essential to ensure functionality of the health-care system. This was especially important in low and middle-income countries, where blood donations were not able to match the demand (1). According to the World Health Organization, the median annual donations per blood centre ranged from 1,300 in low-income countries, 9300 in upper-middle-income countries, and 25,700 in high-income countries (2). A recent study reported that out of 195 countries, 119 countries were not able to meet their blood demand, marking a shortfall of 1,849 blood units per 100,000 population globally (3). 
Blood supply were generally procured from three types of donors, viz. volunteer, non-remunerated donors, family/replacement donors and paid/professional donors. The WHO had advocated for non-remunerated blood donation, as this group of donors had the lowest prevalence of bloodborne infections (4). Globally, there was an increase of 7.8 million blood donations from voluntary unpaid donors from 2013 to 2018 . (2). The blood donation rate in Malaysia, which relies on non-remunerated donors, was estimated at $2.0 \%-2.2 \%(5)$.

In Malaysia, the total number of blood transfusions had raised from 151,500 to 338,600 episodes from 2000 to 2014 (6). The number of blood donations had grown over the same period of years, from 361,898 to 675,315 between $2000-2014$. However, the supply may not meet the needs, as blood utilization may increase gradually due to the advancement in organ and stem cell transplant (7). Additionally, the eligible donors may reduce over time due to an ageing population (8). The recent severe acute respiratory syndrome coronavirus 2 outbreak also caused major impact to the blood supply, where blood supply in the country reported a prominent $40 \%$ reduction in comparison with previous year, from 111,328 bags (Mac-May 2018) to 67,135 bags (Mac-May 2020) (9).

Therefore, there was an urgent need for the blood bank to improvise measures to improve recruitment of new donors and retainment of regular donors. Donors' satisfaction towards the blood bank services was associated with their future donation intentions (10). Previous literatures reported various factors affecting donor satisfaction, including friendliness of the receptionist (7), interpersonal skills demonstrated by the phlebotomists (11), waiting time (12) and staff competence $(13,14)$.

A recent validated questionnaire included items such as cleanliness, snack offered after blood donation, accessibility of the blood bank and blood bank operating hours in measuring donors' satisfaction (15). It is therefore imperative to understand the donors' satisfaction in the local context, as it may affect recruitment and retention of blood donors. To date, we are unaware of local studies examining donors' satisfaction towards blood bank services. This study aimed to explore the satisfaction and experience of blood donors during the blood donation process and their intention to return for donation in future.

\section{Methods}

This was a cross-sectional study conducted using a self-administered questionnaire among blood donors. This study was conducted at the blood centre in Hospital Raja Permaisuri Bainun and two mobile sites which was held at hypermarkets within the Kinta district of the Perak state. All the blood donors who arrived at the study sites were consecutively sampled. We included Malaysian donors who were more than 18 years of age and completed donation in this study. Temporary or permanent deferred blood donors, non-Malaysian, illiterate donors and blood donors with diagnosed psychological illness were excluded.

The questionnaire was developed by the investigators after extensive literature review $(7,11-13,16)$. The questionnaire was initially developed in the Malay language, the national language of Malaysia. The selfdeveloped questionnaire underwent face validation and content validation by two transfusion medicine 
experts. The questionnaire was then underwent a pre-test on 10 respondents to ensure clarity before being used for data collection. Subsequently, a pilot test was conducted among 130 blood donors to examine its validity and reliability, with satisfactory Cronbach alpha ranged from 0.814 to 0.961 . The questionnaire consisted of three domains: i) sociodemographic characteristics ii) donor's satisfaction towards staff iii) donors' experience and satisfaction towards donation process. The two latter domains were evaluated using a 5-point Likert scale.

Sample size was estimated using Raosoft online sample size calculator (Raosoft Inc, 2004) based on the formula for estimation of a proportion with infinite population correction and using a value of 0.5 (50\%) as the desired proportion to be estimated. With a precision of 0.05 , a total of 377 samples was required for the survey. Considering $5 \%$ incomplete questionnaire response, the required samples size was 397 . We distributed 200 sets of questionnaires in the blood centre and 100 sets in each mobile site.

The blood donors were approached after they completed donation. Typically, the respondents completed the questionnaire within an average of 10-15 minutes. Written consent was obtained from all the respondents before participation. The respondents handed in the questionnaires to the designated study personnel immediately after they completed answering. This study had obtained approval from the Medical Research Ethical Committee (NMRR-20-1205-55304). Data collection was conducted in August and September 2020.

The Statistical Package for the Social Sciences (SPSS) for Windows version 24.0 (IBM, New York) was used in data analysis. The sociodemographic of the donors, satisfaction level and experience towards blood donation process were descriptively analysed. The continuous variables were presented as means and standard deviation while the categorical variables were presented as frequency and percentages. Chisquare tests were performed to examine the association between donors' satisfaction, donors' intention to donate blood in the future with their sociodemographic characteristics; to determine the satisfaction level difference between those donated at blood centre and mobile sites. A $p$-value of less than 0.05 will be considered statistically significant.

\section{Results}

Of the 400 questionnaires distributed, 369 (92.3\%) were returned and included in analysis. The mean ( \pm sd) age of the donors was 35.98 ( \pm 10.67$)$ years. Most of the donors were male $(75.1 \%)$, of Malay ethnicity $(60.2 \%)$, married $(59.1 \%)$, with a certificate or diploma degree $(35.8 \%)$, earning between the range of RM2,000 to RM4,000 (40.9\%) and regular donors (65.6\%) (Table 1). A vast majority of the blood donors reported high satisfaction towards the counter services (98.3\%), professionalism of the interviewer (99.0\%), blood taking skill of the staff (97.5\%), politeness and friendliness of the staff (99.5\%) and communication with the staff (98.9\%) (Table 2).

In term of blood donation experience, majority of the blood donors agreed that the blood donation process was smooth and painless (97.0\%), blood donation area was clean (95.7\%) and the waiting time was satisfactory (98.6\%). There was no prominent difference in term of perceived health status before 
and after the blood donation. Minority of the blood donors expressed dissatisfaction towards the parking spaces $(13.4 \%)$, refreshment $(0.8 \%)$, and the blood donation operation hours $(0.8 \%)$. We observed a high overall satisfaction level (99.2\%) and high intention to donate blood again in the future (98.9\%) among the respondents (Table 3). No significant association was established between donors' satisfaction level with their demographic characteristics. Likewise, the satisfaction level between donors who visited the blood centre in hospital and the mobile sites did not differ.

Table 1 Demographic characteristics of donors $(\mathrm{N}=369)$ 


\begin{tabular}{|c|c|c|}
\hline Characteristics & Frequency (n) & Percentage \\
\hline Age (mean $\pm s d$, years) ${ }^{a}$ & $35.98 \pm 10.67$ & \\
\hline \multicolumn{3}{|l|}{ Gender } \\
\hline Male & 277 & 75.1 \\
\hline Female & 92 & 24.9 \\
\hline \multicolumn{3}{|l|}{ Ethnicity } \\
\hline Malay & 222 & 60.2 \\
\hline Chinese & 104 & 28.2 \\
\hline Indian & 33 & 8.9 \\
\hline Others & 10 & 2.7 \\
\hline \multicolumn{3}{|l|}{ Marrital status } \\
\hline Single & 136 & 36.9 \\
\hline Married & 218 & 59.1 \\
\hline Divorce & 15 & 4.1 \\
\hline \multicolumn{3}{|l|}{ Occupation ${ }^{b}$} \\
\hline Government & 107 & 30.6 \\
\hline Private & 115 & 32.9 \\
\hline Self-employed & 67 & 19.1 \\
\hline Student & 42 & 12.0 \\
\hline Unemployed & 19 & 5.4 \\
\hline \multicolumn{3}{|l|}{ Education level } \\
\hline Bachelor degree and above & 105 & 28.5 \\
\hline Certificate or diploma & 132 & 35.8 \\
\hline Secondary & 128 & 34.7 \\
\hline Primary & 2 & 0.5 \\
\hline No formal education & 2 & 0.5 \\
\hline \multicolumn{3}{|l|}{ Income ${ }^{b}$} \\
\hline$<\mathrm{RM} 2,000$ & 106 & 30.3 \\
\hline RM2,000-RM4,000 & 143 & 40.9 \\
\hline
\end{tabular}




\begin{tabular}{|c|c|c|}
\hline RM4,001-RM8,000 & 66 & 18.9 \\
\hline$>\mathrm{RM} 8,000$ & 35 & 10.0 \\
\hline \multicolumn{3}{|l|}{ Donor Type } \\
\hline New donor & 39 & 10.6 \\
\hline Regular donor & 242 & 65.6 \\
\hline Lapsed donor (last donated > 2 years) & 88 & 23.8 \\
\hline \multicolumn{3}{|l|}{ Type setting } \\
\hline Blood centre & 194 & 52.6 \\
\hline Mobile sites ${ }^{c}$ & 175 & 47.4 \\
\hline
\end{tabular}

${ }^{a}$ Age is expressed as mean \pm standard deviation

${ }^{b}$ Missing response $(n=19)$

${ }^{\mathrm{C}}$ Mobile sites comprised of two hypermarkets in the Kinta district of Perak

Table 2 Satisfaction towards blood bank personnel $(n=369)$

\section{Statement}

36598.9

3. I am satisfied with the services given by the interviewer

$360 \quad 97.5$

4. I am satisfied with the skills of the staff who took my blood

$367 \quad 99.5$

5. The staff on duty are friendly and polite

36598.9

6. The staff on duty are always ready to listen/help me

36598.9

7. After donating blood, the staff on duty thanks me amiably

$365 \quad 98.9$


Table 3 Experience and satisfaction towards blood donation process $(n=369)$

\begin{tabular}{|lll|}
\hline Statement & \multicolumn{2}{l}{ Agree or strongly agree } \\
\cline { 2 - 3 } & $\mathbf{n}$ & $\%$ \\
\hline 1. I felt healthy before blood donation & 363 & 98.3 \\
\hline 2. The blood donation is smooth and painless & 358 & 97.0 \\
\hline 3. I felt healthy after blood donation & 360 & 97.5 \\
\hline 4. I am satisfied with the cleanliness around the blood donation area & 353 & 95.7 \\
\hline 5. Refreshment served after the blood donation is satisfactory & 333 & 90.2 \\
\hline 6. Parking spaces at the blood donation area is satisfactory & 149 & 76.8 \\
\hline 7. I am satisfied with the blood donation operation hours & 355 & 96.2 \\
\hline 8. I am satisfied with the waiting time before blood donation & 364 & 98.6 \\
\hline 9. I am satisfied with the overall blood donation process & 366 & 99.2 \\
\hline 10. I will donate blood again in the future & 365 & 98.9 \\
\hline
\end{tabular}

a Satisfaction towards parking spaces was collected among donors at blood centre $(n=194)$

\section{Discussion}

To our best knowledge, this was the first local study which described the satisfaction and experience of blood donors in the blood center within a public tertiary hospital and mobile sites in Malaysia. Generally, the donors reported high satisfaction towards the blood bank staff and had pleasant experience during the blood donation process. All the donors had high intention to donate blood again in the future. The study outcomes informed the gap of donors' care and may serve as a guide for the policymakers on areas of focus to improve services related to blood donors' satisfaction.

In this study, the respondents elicited good satisfaction towards the reception services provided by the blood bank. A recent study in Brazil reported low satisfaction towards the reception service provided by the staff, which was also perceived as highly important by the donors. (15). Meanwhile, friendliness and availability of the blood bank staff were also rated highly by our respondents. The professionalism and attitude of the blood bank personnel had significant impact on blood donors' satisfaction level $(7,13)$. In Malaysia, all healthcare personnel were required to provide a fair, professional and friendly services towards their clients, in accordance to the Ministry of Health Clients Charter. To improve service quality, educational programs infused with donor-specific feedback may instill deeper understanding among the front-line blood bank personnel on donors' satisfaction (17). 
The respondents demonstrated high satisfaction towards the phlebotomists' blood taking and interpersonal skills, where $97 \%$ of the respondents agreed that the donation process was smooth and painless. This was also reflected in the donors' experience, as there was no prominent difference in perceived health status before and after blood donation. The competence and blood taking skills of the phlebotomist was found to be highly associated with the donor's satisfaction and experience $(7,13)$. Additionally, good phlebotomist interpersonal skills may reduce the events of vasovagal reactions among blood donors (11). Apart from adhering to the phlebotomy practices guidelines (18), regular training of the blood bank phlebotomy staff in educational intervention programs may enhance standardization and improve quality of phlebotomy practices (19).

In contrast with other developed countries, the Malaysian blood donors were not remunerated with special incentives such as travelling compensation, time-off, monetary rewards or tax rebate (20). Nevertheless, all the blood donors who completed donation were given light refreshment, in accordance to the WHO Safe Blood Donation Guidelines (21). This study revealed that a minority of the blood donors had low satisfaction towards the refreshment provided by the blood bank. This might be attributed to the limited options of snack and drinks in the local blood donation sites. Snack offered after blood donation may not improve overall satisfaction but may lead to dissatisfaction if the expectation was not met (15). Hence, provision of more refreshment varieties may serve as a possible way to ensure blood donors' satisfaction (22).

Meanwhile, the satisfaction of blood donors towards the parking spaces at the blood center within the hospital was also assessed. Accessibility of the blood center was considered as one of the components which may affect long-term satisfaction among the blood donors $(15,23)$. Similarly, a study in Brazil found that blood donors were concerned regarding availability of car park when asked about what might influence their satisfaction (16). While requesting more car parks slots from the blood donors can serve as a short-term relief, the need may not be sustained as the vehicle possession per resident ratio was constantly increasing (24). Although organization of mobile blood drives at venues with large parking bays may alleviate the problem, this may not be practiced during a pandemic outbreak when movement control order was enforced. The feasibility of alternative strategies such as provision of two-way shuttle transport for the blood donors, provision of special reimbursement or discount for using public transport and drive-through blood donation services should be explored to assess its efficacy, safety, impact on blood donors' satisfaction and their intention to donate $(25,26)$

This study had several limitations. We found that majority of the respondents had high overall satisfaction towards the blood donation process and high intention to donate blood again in the future. This was in congruence to previous studies which reported similar association $(14,27)$. While donors' intention to return was a reliable predictor of actual return $(14,28)$, it was arguably a surrogate marker as the actual return behaviors were not studied (10). Also, although the survey was anonymous in nature, it was highly susceptible to acquiescence bias, as the respondents may have the tendency to please the blood bank personnel who they handed the survey form to upon completion. Employment of electronic data collection forms in future studies may reduce the bias and provide a more truthful depiction of the 
donors' satisfaction. A single-center design may also limit the generalizability of the findings to blood centers in other localities.

\section{Conclusion}

The blood donors demonstrated high level of satisfaction towards the staff and blood donation process. Further study is required to examine whether the high intention to return for donation in future can be translated into actual donation behavior.

\section{References}

1. Custer, B., Zou, S., Glynn, S. A., Makani, J., Tayou Tagny, C., El Ekiaby, M., Sabino, E. C., Choudhury, N., Teo, D., Nelson, K., Peprah, E., Price, L., \& Engelgau, M. M. (2018). Addressing gaps in international blood availability and transfusion safety in low- and middle-income countries: A NHLBI workshop. Transfusion, 58(5), 1307-1317. https://doi.org/10.1111/trf.14598

2. World Health Organization (2019). Blood Safety and Availability. https://www.who.int/newsroom/fact-sheets/detail/blood-safety-and-availability

3. Roberts, N., James, S., Delaney, M., \& Fitzmaurice, C. (2019). The global need and availability of blood products: A modelling study. The Lancet. Haematology, 6(12), e606-e615. https://doi.org/10.1016/S2352-3026(19)30200-5

4. World Health Organization. Towards $100 \%$ voluntary blood donation. A global framework for action (2010). https://www.who.int/bloodsafety/publications/9789241599696/en/

5. Ministry of Health Malaysia. Annual Report Blood Transfusion Services. 2011-2015.

6. Lim, M. L., S. H. Thock, A. K. G. Tan and S. L. Gwee. (2018). Determinants of blood donation status in Malaysia: Profiling the non-donors, occasional donors and regular donors. Kajian Malaysia, 36(1): 43-62.

7. Nguyen DD, Devita DA, Hirschler NV, Murphy EL. (2008). Blood donor satisfaction and intention of future donation. Transfusion, 48(4):742-8.

8. Wooi Seong K, Raffeal V, Ayob Y. (2014). Adopting a proactive approach to blood shortages: experience from the National Blood Centre, Malaysia. VOXS, 9(1):189

9. The Star. Health DG urges public to donate blood due to shortage at blood centres. https://www.thestar.com.my/news/nation/2020/05/20/health-dg-urges-public-to-donate-blood-dueto-shortage-at-blood-centres. Date: 20 May 2020. Date accessed: 14 Oct 2020

10. Bednall, T. C., Bove, L. L., Cheetham, A., \& Murray, A. L. (2013). A systematic review and meta-analysis of antecedents of blood donation behavior and intentions. Social Science \& Medicine, 96, 86-94. https://doi.org/10.1016/j.socscimed.2013.07.022

11. Stewart KR, France CR, Rader AW, Stewart JC. (2006). Phlebotomist interpersonal skill predicts a reduction in reactions among volunteer blood donors. Transfusion, 46:1394-401. 
12. McKeever, T., Sweeney, M. R., \& Staines, A. (2006). An investigation of the impact of prolonged waiting times on blood donors in Ireland. Vox Sanguinis, 90(2), 113-118.

https://doi.org/10.1111/j.1423-0410.2006.00734.x

13. Vavić, N., Pagliariccio, A., Bulajić, M., Marinozzi, M., Miletić, G., \& Vlatković, A. (2012). Blood donor satisfaction and the weak link in the chain of donation process. Transfusion and Apheresis Science, 47(2), 171-177. https://doi.org/10.1016/j.transci.2012.06.025

14. Weidmann, C., Müller-Steinhardt, M., Schneider, S., Weck, E., \& Klüter, H. (2013). Donor satisfaction with a new german blood donor questionnaire and intention of the donor to return for further donations. Transfusion Medicine and Hemotherapy, 40(5), 356-361. https://doi.org/10.1159/000354844

15. Martinez, E. Z., Tamaribuchi, R. A., Zucoloto, M. L., \& Trovão, A. C. G. B. (2020). Recommendations for application and interpretation of the blood donor satisfaction questionnaire(BDSQ). Hematology, Transfusion and Cell Therapy, S2531137920300638. https://doi.org/10.1016/j.htct.2020.03.007

16. Trovão, A. C. G. B., Zucoloto, M. L., \& Martinez, E. Z. (2019). Development of a blood donor satisfaction questionnaire (BDSQ). Hematology, Transfusion and Cell Therapy, S2531137919301634. https://doi.org/10.1016/j.htct.2019.09.004

17. Kennedy, D. M. (2017). Creating an excellent patient experience through service education. Journal of Patient Experience, 4(4), 156-161. https://doi.org/10.1177/2374373517718351

18. Dhingra, N., Safe Injection Global Network, \& World Health Organization. (2010). WHO guidelines on drawing blood: Best practices in phlebotomy. http://www.ncbi.nlm.nih.gov/books/NBK138650/

19. Bölenius, K., Brulin, C., \& Graneheim, U. H. (2014). Personnel's experiences of phlebotomy practices after participating in an educational intervention programme. Nursing Research and Practice, 2014. https://doi.org/10.1155/2014/538704

20. Abolghasemi, H., Hosseini-Divkalayi, N. S., \& Seighali, F. (2010). Blood donor incentives: A step forward or backward. Asian Journal of Transfusion Science, 4(1), 9-13. https://doi.org/10.4103/0973-6247.59385

21. Safe blood and blood products. Safe blood donation Module 1. (2009). https://www.who.int/bloodsafety/transfusion_services/Module1.pdf

22. New Zealand Blood Service. Donor Refreshment. (2019). https://www.nzblood.co.nz/giveblood/donating/the-donation-process/donor-refreshments/

23. Mohammed, S., \& Essel, H. B. (2018). Motivational factors for blood donation, potential barriers, and knowledge about blood donation in first-time and repeat blood donors. BMC hematology, 18, 36. https://doi.org/10.1186/s12878-018-0130-3

24. Gilbert, D. (2015). Car parking is a clinical quality issue. BMJ, 350(apr14 10), h1312-h1312. https://doi.org/10.1136/bmj.h1312

25. Hains IM, Marks A, Georgiou A, Westbrook JI. (2011). Non-emergency patient transport: what are the quality and safety issues? A systematic review. Int J Qual Health Care,23(1):68-75. doi:

10.1093/intqhe/mzq076

Page $11 / 12$ 
26. Syed, S. T., Gerber, B. S., \& Sharp, L. K. (2013). Traveling towards disease: transportation barriers to health care access. Journal of community health, 38(5), 976-993. https://doi.org/10.1007/s10900013-9681-1

27. Germain, M., Glynn, S. A., Schreiber, G. B., Gélinas, S., King, M., Jones, M., Bethel, J., \& Tu, Y. (2007). Determinants of return behavior: A comparison of current and lapsed donors. Transfusion, 47(10), 1862-1870. https://doi.org/10.1111/j.1537-2995.2007.01409.x

28. Masser, B. M., Bednall, T. C., White, K. M., \& Terry, D. (2012). Predicting the retention of first-time donors using an extended Theory of Planned Behavior: DONOR RETENTION. Transfusion, 52(6), 1303-1310. https://doi.org/10.1111/j.1537-2995.2011.03479.x 